\title{
Rubber Composites Based on Polar Elastomers with Incorporated Modified and Unmodified Magnetic Filler
}

\author{
Ján Kruželák, ${ }^{1}$ Richard Sýkora, ${ }^{1}$ Rastislav Dosoudil, ${ }^{2}$ and Ivan Hudec ${ }^{1}$ \\ ${ }^{1}$ Department of Plastics and Rubber, Institute of Polymer Materials, Faculty of Chemical and Food Technology, \\ Slovak University of Technology, Radlinského 9, 81237 Bratislava, Slovakia \\ ${ }^{2}$ Department of Electromagnetic Theory, Faculty of Electrical Engineering and Information Technology, \\ Slovak University of Technology, Il'kovičova 3, 81219 Bratislava, Slovakia \\ Correspondence should be addressed to Ján Kruželák; jan.kruzelak@stuba.sk
}

Received 28 January 2016; Revised 17 March 2016; Accepted 4 May 2016

Academic Editor: Luigi Nicolais

Copyright (C) 2016 Ján Kruželák et al. This is an open access article distributed under the Creative Commons Attribution License, which permits unrestricted use, distribution, and reproduction in any medium, provided the original work is properly cited.

Rubber magnetic composites were prepared by incorporation of unmodified and surface modified strontium ferrite into rubber matrices based on NBR and NBR/PVC. Strontium ferrite was dosed to the rubber matrices in concentration scale ranging from 0 to $100 \mathrm{phr}$. The main goal was to investigate the influence of the type of ferrite on the curing process, physical-mechanical and magnetic properties of composites. The mutual interactions between the filler and rubber matrices were investigated by determination of cross-link density and SEM analysis. The incorporation of magnetic fillers leads to the increase of cross-link density and remanent magnetic induction of composites. Moreover, the improvement of physical-mechanical properties was achieved in dependence on the content of magnetic fillers. Surface modification of ferrite contributed to the enhancement of adhesion on the interphase filler-rubber. It can be stated that ferrite exhibits reinforcing effect in the composite materials and this reinforcing behavior was emphasized with the increase in polarity of the rubber matrix.

\section{Introduction}

Rubber magnetic composites belong to the well-known group of smart materials which can be prepared by incorporation of various magnetic fillers into different rubber matrices [1-6]. The investigation of the preparation and properties of rubber magnetic composites has also been the subject of interest of some of our previous scientific works [7-9]. The advantage of rubber magnetic composites is that their properties can be modified for the requirements of specific applications. The final properties of composites are strongly dependent on characteristics of elastomer matrix especially. However, by integration of magnetic materials, new properties and technological abilities can be provided [10, 11].

Among the most widely used magnetic materials belong ferrites. Ferrites are class of technologically important magnetic materials with strong magnetocrystalline anisotropy and high values of magnetic characteristics (mainly coercivity and remanent magnetic induction) [12-15]. Besides this, they exhibit good chemical stability with a high resistance to solvents, salts, lubricants, alkalis, harmful gases, soft acids, and atmospheric effects, too. Ferrites may occur in several crystallographic modifications, but in terms of possible applications ferrites with hexagonal structure express the biggest interest [16]. Ba and Sr ferrites are the most commonly used magnetic powdery fillers $[17,18]$. Ferrite permanent magnets of general formula $\mathrm{SrFe}_{12} \mathrm{O}_{19}$ or $\mathrm{BaFe}_{12} \mathrm{O}_{19}$ contain approximately $80 \%$ of iron oxide and $20 \%$ of strontium or barium.

By incorporation of magnetic polycrystalline ferrites into various rubber matrices it is possible to prepare composite materials referred to as rubber magnets. Due to their elasticity and easy process ability, they are suitable for applications, in which good elasticity and high flexibility are required. These attributes in combination with unique magnetic characteristics rank them among the progressive developing materials which have already found the utilization in many high-tech applications. Rubber composites with magnetic fillers are able to sensitively respond to vibrations and absorb oscillations 
of various wavelengths. They can also change magnetic and mechanical properties at different forms of strain. Therefore they have been found to be applied in dc-motors, new types of recording appliances, magnetic screeners, microwave and radar technology, biotechnology, in motor parts, vibration absorbers, variable impedance surfaces, sensors of magnetic and electromagnetic fields, memory devices, inductor cores, and many other technological applications [19-22].

In this work, acrylonitrile butadiene rubber NBR and mechanically compounded blend formed from acrylonitrile butadiene rubber and polyvinyl chloride NBR/PVC were used as rubber matrices with different polarity. The same type of strontium ferrite in unmodified and surface modified form in various loading level was incorporated into elastomer matrices in order to prepare rubber magnetic composites. The main goal was to observe the influence of strontium ferrite content on the curing process of rubber compounds and subsequently to investigate physical-mechanical and magnetic properties of prepared composites. The investigation of physical and chemical cross-link density with surface morphology of composite materials was also part of experimental study in order to better clarify the interactions and adhesion between the filler and elastomer matrices in dependence on their chemical nature.

\section{Experimental}

2.1. Materials. Acrylonitrile butadiene rubber EUROPRENE N3330 (NBR, Polimeri, Italy, content of acrylonitrile: 33\%) and blend acrylonitrile butadiene rubber, polyvinyl chloride under the trade name N OZO 7028 (NBR/PVC, Polimeri, Italy, NBR/PVC weight ratio 70/30, content of acrylonitrile: $19.5 \%$ ), were chosen as rubber matrices. Anisotropic strontium hexaferrite $\mathrm{SrFe}_{12} \mathrm{O}_{19}$, commercially marked as FD 8/24 provided by Magnety, Světlá Hora, Czech Republic, was incorporated into rubber matrices in two forms. Ferrite, surface modified with polyvinyl alcohol (PVAL), is in the work specified as FD0. Surface modification of ferrite was performed by mixing of ferrite particles with PVAL emulsion followed by subsequent drying at laboratory temperature. Ferrite, specified as FD1, was unmodified type of the same strontium ferrite. The content of magnetic filler was changed from 0 to 100 phr. The detailed specification of applied strontium ferrites is mentioned in Table 1. A standard semi-EV sulfur curing system consisting of zinc oxide 3 phr (Slovlak, Košeca, Slovakia), stearic acid 2 phr (Setuza, Ústí nad Labem, Czech Republic), N-cyclohexyl-2-benzothiazole sulfenamide CBS $1.5 \mathrm{phr}$ (Duslo, Šal'a, Slovakia), and sulfur $1.3 \mathrm{phr}$ (Siarkopol, Tarnobrzeg, Poland) was used for cross-linking of rubber matrices. Phr stands for parts per hundred of rubber.

\subsection{Methods}

2.2.1. Preparation and Curing of Rubber Compounds. The rubber compounds were prepared in the laboratory mixer Brabender in the two mixing steps. The temperature of chamber was set up to $90^{\circ} \mathrm{C}$ and the mixing process was carried out at the rotor speed of $50 \mathrm{rpm}$. First, the rubber was
TABLE 1: Characteristics of strontium ferrite.

\begin{tabular}{|c|c|c|}
\hline Characteristics & FD0 & FD1 \\
\hline Specific surface area $\left(\mathrm{m}^{2} / \mathrm{g}\right)$ & 3.3 & 4.06 \\
\hline Total porosity (\%) & 54.94 & 55.62 \\
\hline $\begin{array}{l}\text { Specific volume of pores } \\
\left(\mathrm{cm}^{3} / \mathrm{g}\right)\end{array}$ & 0.264 & 0.254 \\
\hline Density $\left(\mathrm{g} / \mathrm{cm}^{3}\right)$ & 4.13 & 4.73 \\
\hline Coercivity (kA/m) & 116 & 117 \\
\hline $\begin{array}{l}\text { Remanent magnetic } \\
\text { induction }(\mathrm{T})\end{array}$ & 0.116 & 0.117 \\
\hline $\begin{array}{l}\text { Maximum magnetic } \\
\text { induction }(\mathrm{T})\end{array}$ & 1.150 & 1.260 \\
\hline
\end{tabular}

plasticated, and then activators and filler were compounded. The mixing of ingredients in the first step was performed for $9 \mathrm{~min}$ at a temperature range $90-95^{\circ} \mathrm{C}$. In the second step ( $4 \mathrm{~min}, 90-95^{\circ} \mathrm{C}$ ), sulfur together with accelerator was introduced. After that, the mixed rubber compounds were shaped into thin sheets by using the two-roll calender.

The curing characteristics were investigated from the corresponding curing isotherms measured by Rheometer Monsanto R100 at $150^{\circ} \mathrm{C}$. The rubber compounds were cured at $150^{\circ} \mathrm{C}$ with regard to their optimum cure time under a pressure of $15 \mathrm{MPa}$. The hydraulic press FONTIJNE was employed to carry out the curing process.

2.2.2. Determination of Chemical Cross-Link Density of Composites. The chemical cross-link density $\nu_{c h}$ of composites was determined based on swelling of samples in acetone, in which the samples were swelled within the time. The weight of samples was measured every hour until the equilibrium swelling was reached. The experiments were performed in laboratory conditions and the swelling time was 30 hours. When the equilibrium swelling degree was reached, the Krause modified Flory-Rehner equation (1) for filled vulcanizates was used to evaluate the cross-link density [23]:

$$
\nu_{\mathrm{ch}}=-\frac{V_{r 0}}{V_{S}} \frac{\ln \left(1-V_{r}\right)+V_{r}+\chi V_{r}^{2}}{V_{r}^{1 / 3} V_{r 0}^{2 / 3}-0.5 V_{r}},
$$

where $v_{\mathrm{ch}}$ is the cross-link density $\left(\mathrm{mol} / \mathrm{cm}^{3}\right), V_{r 0}$ the volume fraction of rubber in equilibrium swelling sample of vulcanizate in absence of fillers, $V_{r}$ the volume fraction of rubber in equilibrium swelling sample of filled vulcanizate, $V_{S}$ the molar volume of solvent (for acetone $=73.519 \mathrm{~cm}^{3} / \mathrm{mol}$ ), $\chi$ the Huggins interaction parameter (for NBR, NBR/PVC-acetone $\chi=0.3692$ ). Consider

$$
V_{r 0}=\frac{V_{k 0}}{V_{k 0}+V_{n}},
$$

where $V_{n}$ is the volume of solvent in sample of vulcanizate in equilibrium swelling and $V_{k 0}$ is the volume of rubber in sample of vulcanizate in absence of fillers. Consider

$$
\begin{aligned}
V_{k 0} & =a \cdot \frac{100}{100+x} \cdot \frac{1}{\rho_{k}}, \\
V_{r} & =\frac{V_{k}}{V_{k}+V_{n}},
\end{aligned}
$$


where $V_{k}$ is the volume of rubber in sample of filled vulcanizate. Also consider

$$
V_{k}=a \cdot \frac{100}{100+(x+p)} \cdot \frac{1}{\rho_{k}},
$$

where $x$ is the total amount of additives in sample of vulcanizate, $p$ the total amount of fillers in sample of vulcanizate, $\rho_{k}$ the density of rubber $\left(\rho_{\mathrm{NBR}}=0.97 \mathrm{~g} / \mathrm{cm}^{3}, \rho_{\mathrm{NBR} / \mathrm{PVC}}=1.05 \mathrm{~g} /\right.$ $\mathrm{cm}^{3}$ ), $a$ the initial weight of sample of vulcanizate before swelling.

2.2.3. Determination of Total Cross-Link Density of Composites. The determination of the total cross-link density $v_{t}$ is based on deformation measurements of samples by introducing the Mooney-Rivlin equation [24] (5), with using formula (6), too:

$$
\frac{\sigma}{2\left(\alpha-\alpha^{-2}\right)}=C_{1}+\frac{C_{2}}{\alpha}
$$

where $\sigma$ is the tension (MPa), $\alpha$ is the relative extension (\%), and $C_{1}, C_{2}$ are the constants. Consider

$$
v_{t}=\frac{2 C_{1}}{R T}
$$

where $R=8.314 \mathrm{~J} / \mathrm{K} \cdot \mathrm{mol}$ and $T=293.15 \mathrm{~K}$.

From the graphical dependence $\sigma /\left(2\left(\alpha-\alpha^{-2}\right)\right)=f\left(\alpha^{-1}\right)$ the equation of straight line was obtained, which was extrapolated to zero value. $C_{1}$ is then calculated as the line section on the axis $\sigma /\left(2\left(\alpha-\alpha^{-2}\right)\right)$ and $C_{2}$ as the slope of a straight line.

The measurements were performed at laboratory temperature by using the Inspekt desk $5 \mathrm{kN}$ apparatus (Metrotest). The samples were stretched up to $100 \%$ deformation; the deformation velocity was set up to $10 \mathrm{~mm} / \mathrm{min}$.

\subsubsection{Determination of Physical-Mechanical Properties of} Composites. The tensile properties of rubber magnetic composites were determined by employing Zwick Roell/Z 2.5 appliance. The measurements were carried out in accordance with the valid technical standards at laboratory temperature and cross-head speed of $500 \mathrm{~mm} / \mathrm{min}$. The tested composites were cut into the double side dumbbell-shaped test specimens (width $6.4 \mathrm{~mm}$, length $8 \mathrm{~cm}$, and thickness $2 \mathrm{~mm}$ ). The hardness was measured by using durometer and the unit was expressed in Shore A.

2.2.5. Microscopic Analysis of Composites. The scanning electron microscope Tesla BS 300 with digitizing unit Tescan equipped with Wintip software was used to observe the surface morphology and microstructure of rubber magnetic composites. The samples were fractured into small pieces with surface area of $3 \times 2 \mathrm{~mm}$ after they were cooled down in liquid nitrogen under the glass transition temperature. The surface of samples was covered with a thin layer of gold and inserted into the SEM. The magnification was set up to 3000x.

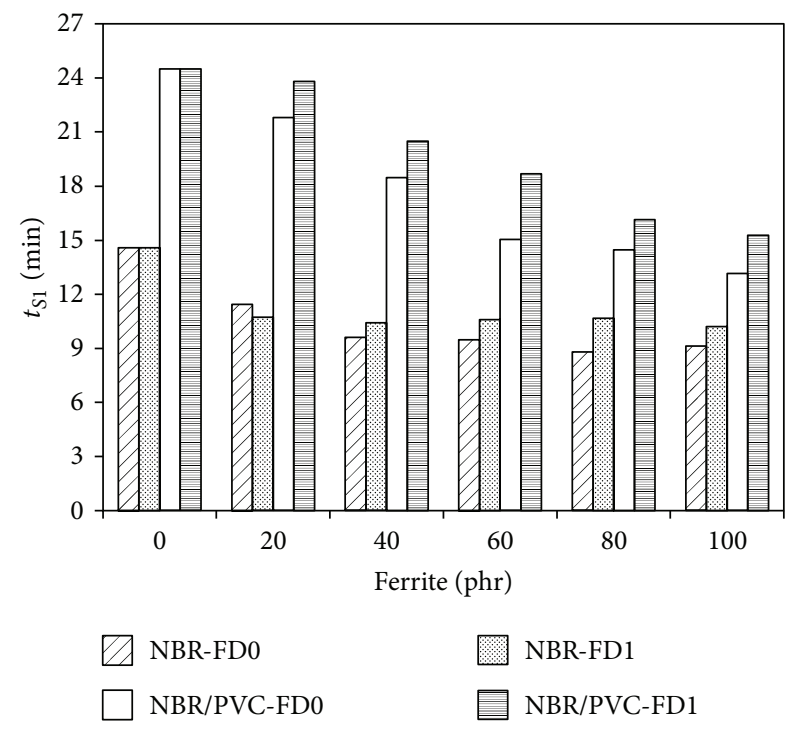

FIGURE 1: Influence of ferrites content on scorch time $t_{S 1}$ of rubber compounds.

2.2.6. Determination of Magnetic Properties of Composites. Magnetic characteristics of composites were evaluated by using magnetometer TVM-1 at maximum coercivity of $H_{m}=$ $750 \mathrm{kA} / \mathrm{m}$. The basic principle of measurement is induction method of scanning of scattering magnetic flux $\Phi$ induced by magnetic vibrating sample. Magnetic field is generated by means of two cores of Weiss electromagnet at a minimum distance of poles adapters $7.5 \mathrm{~mm}$. The induced tension proportional to time dependence of magnetic flux in the sample is scanned with the system of four small cores. The cores eliminate the influence of time instability of electromagnet magnetic fields and the change of magnetic flux is directly proportional to magnetic induction $B$. The specimens for the magnetic characteristics evaluation were of prism shape $(8 \times$ $4 \times 4 \mathrm{~mm})$.

\section{Results and Discussion}

3.1. Influence of Ferrite Content on Curing Process and CrossLink Density of Composites. The influence of strontium ferrite content on curing process was evaluated based on determination of curing characteristics, that is, the optimum cure time $t_{\mathrm{C} 90}$, the scorch time $t_{S 1}$, and the difference between the maximum and minimum torque $d M$. From Figure 1 it becomes evident that the presence of strontium ferrite in rubber formulations caused the reduction of scorch time of both NBR and also NBR/PVC based rubber compounds. When $20 \mathrm{phr}$ of ferrite FD0 was dosed to the rubber compound based on NBR, the scorch time decreased in 3 min. With increasing of ferrite FD0 content, the next slight decrease of the scorch time was recorded. The application of unmodified ferrite FD1 into NBR based rubber compounds leads also to the reduction of scorch time. The similar decreasing tendency of $t_{S 1}$ with increasing of magnetic filler content was shown also in the case of rubber compounds based on NBR/PVC. As seen in Figure 1, the biggest drop of scorch time exhibited 

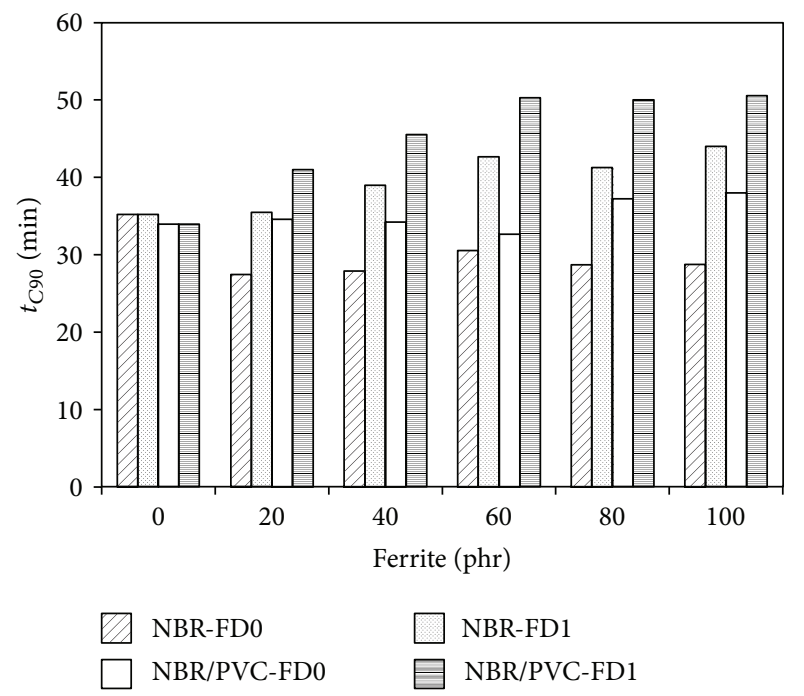

FIGURE 2: Influence of ferrites content on optimum cure time $t_{C 90}$ of rubber compounds.

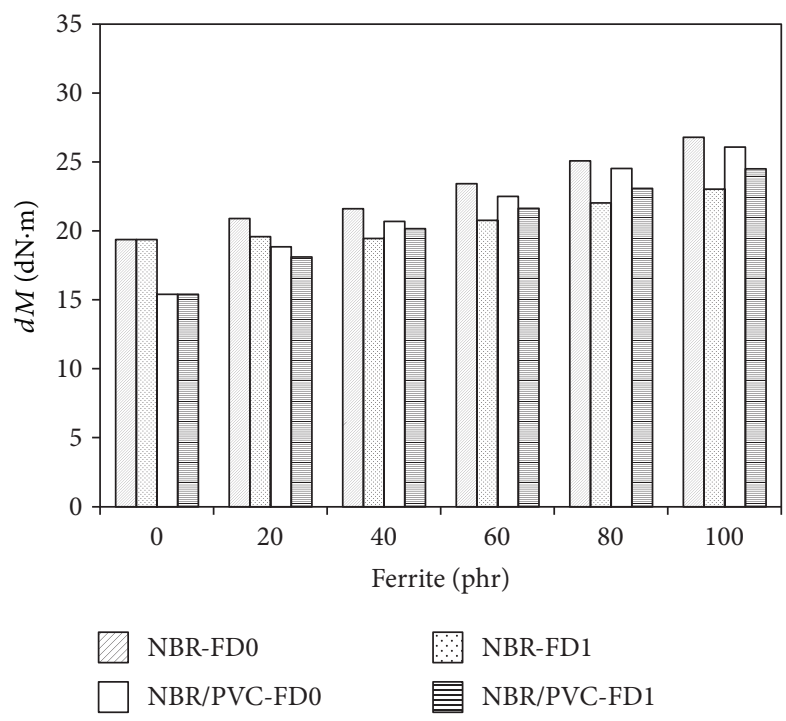

FIGURE 3: Influence of ferrites content on torque difference $d M$ of rubber compounds.

rubber compounds filled with modified ferrite FD0. At the maximum ferrite content, the scorch time was reduced in more than 10 minutes when compared to the reference, unfilled sample. The influence of the type and content of strontium ferrite on the optimum cure time of tested rubber compounds seems to be ambiguous (Figure 2). Generally, it might be stated that no significant changes in the optimum cure time of rubber compounds were observed by applying modified ferrite FD0. In the case of rubber compounds filled with unmodified ferrite FD1, the incorporation of magnetic filler resulted in prolongation of the time needed for optimum cross-linking. The torque difference $d M$ showed increasing tendency with increasing content of strontium ferrites (Figure 3). This points out to the increase in cross-link density of prepared composites with the increase in ferrites loading.

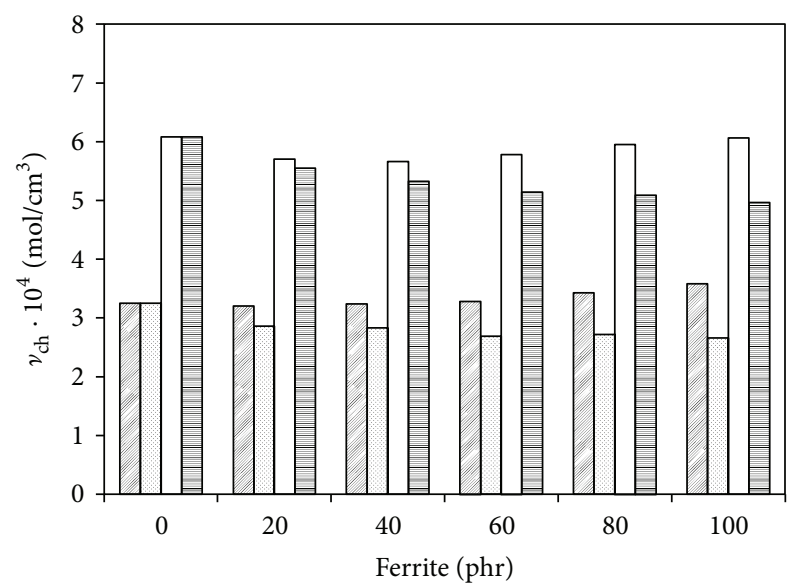

NBR-FD0

NBR-FD1

NBR/PVC-FD0

NBR/PVC-FD1

FIGURE 4: Influence of ferrites content on chemical cross-link density $v_{\text {ch }}$ of composites.

From Figure 3 it is also possible to observe that, in the case of both NBR and also NBR/PVC based rubber compounds, higher values of torque difference showed composites filled with modified ferrite FD0 when compared to equivalent composites filled with unmodified FD1 filler, which also refers to the higher cross-link density of these composites.

The cross-link density of tested composites was determined by using the two different methods. The chemical cross-link density $\nu_{\text {ch }}$ was evaluated based on equilibrium swelling method, while deformation behavior of samples was utilized to determine the total cross-link density $v_{t}$ of prepared composites. When the applied solvent diffuses into the cured samples, it is able to disrupt all physical interactions between the rubber chain segments without breakage of chemical cross-links. After the equilibrium swelling is reached, the chemical cross-link density can be calculated by using the Flory-Rehner equation (1). The point of the second method is stretching of the samples to the low deformation degree, during which, the disruption neither physical nor chemical interactions between the rubber chains is not expected. In this manner, the concentration of all cross-links (chemical and physical) in the analyzed samples is possible to investigate. The physical cross-link density $v_{\mathrm{ph}}$ can be then readily evaluated as the difference between the total and chemical cross-link density. The physical cross-link density can be considered as to be a sum of polymer-polymer physical interactions and polymer-filler physical interactions. But also various intermolecular and intramolecular entanglements are part of the physical cross-link density.

It becomes clearly apparent from Figure 4 that composites based NBR/PVC exhibited nearly twofold higher chemical cross-link density $v_{\mathrm{ch}}$ in comparison with corresponding composites with NBR matrix. As also possible to see, the chemical cross-link density of composites was found not to be influenced by the presence of magnetic fillers, as $\nu_{\mathrm{ch}}$ values fluctuated in the low range almost independently on the amount of magnetic fillers. Only the cross-link density of 


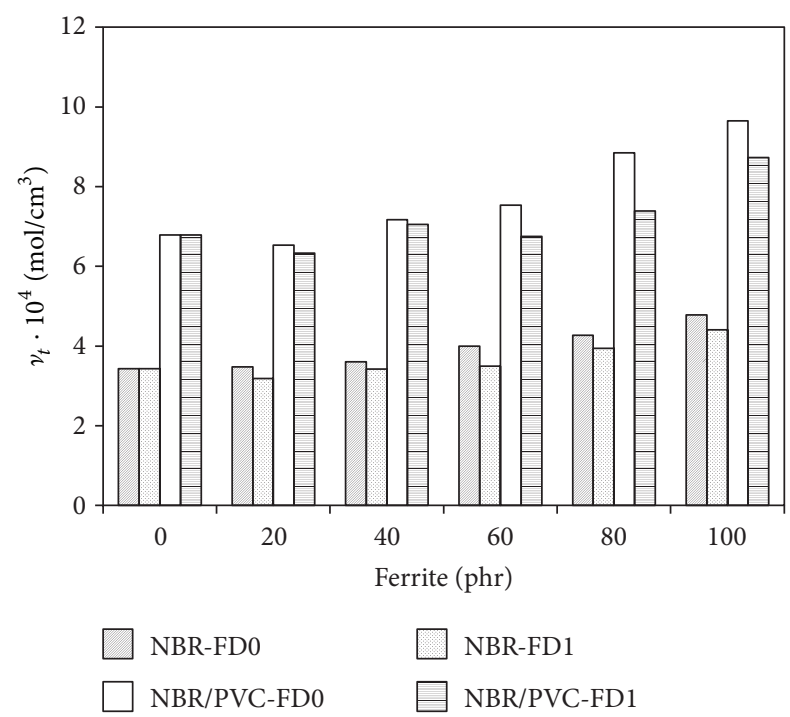

FIGURE 5: Influence of ferrites content on total cross-link density $v_{t}$ of composites.

composites based on NBR/PVC filled with FD1 filler seems to show slight decreasing tendency with increasing content of the applied strontium ferrite. On the other hand, the positive effect of strontium ferrites on the total cross-link density $v_{t}$ was spotted in all tested composites. As illustrated in Figure 5, the incorporation of magnetic fillers into rubber matrices resulted in the increase of their cross-linking degree in dependence on the amount of strontium ferrites. The achieved results also correlate with the dependence of torque difference on the type of ferrite (Figure 3), suggesting that higher torque difference of composites filled with modified ferrite FD0 was reflected in higher cross-link density of the equivalent composites. The physical cross-link density $\nu_{\text {ph }}$ of all composite materials was much lower compared to $v_{\mathrm{ch}}$. But while the chemical cross-link density of composites was not affected by the presence of magnetic filler, the physical cross-link density of all tested composites showed increasing tendency with doping content of strontium ferrites (Figure 6). The highest physical cross-link density and the most significant increase of $v_{\mathrm{ph}}$, in dependence on strontium ferrite content, were possible to be seen in the case of composites based on NBR/PVC. Based upon the increase in the physical cross-link density of prepared composites with increasing content of magnetic fillers, it is suggested that some physical interactions between ferrites and elastomer matrices are formed. Ferrites are complex compounds consisting of iron oxides and oxides of other metallic elements with common formula $\mathrm{MeFe}_{12} \mathrm{O}_{19}$ $(\mathrm{Me}=\mathrm{Sr}, \mathrm{Ba}$, etc.). The structure of hexagonal ferrites reveals that outside layers of ferrite crystals are formed by oxygen ions, while iron ions are placed inside the ferrite structure [25]. Due to the high polarity of oxygen ions present on the surface of ferrite crystals and cyano groups $(-\mathrm{C} \equiv \mathrm{N})$ present in the structure of NBR, it is expected that polar interactions between particles of ferrites and acrylonitrile-structural units of NBR are formed. The highest increase in $\nu_{\mathrm{ph}}$ of magnetic composites based on NBR/PVC can be attributed to the polar interactions between oxygen ions of magnetic fillers and

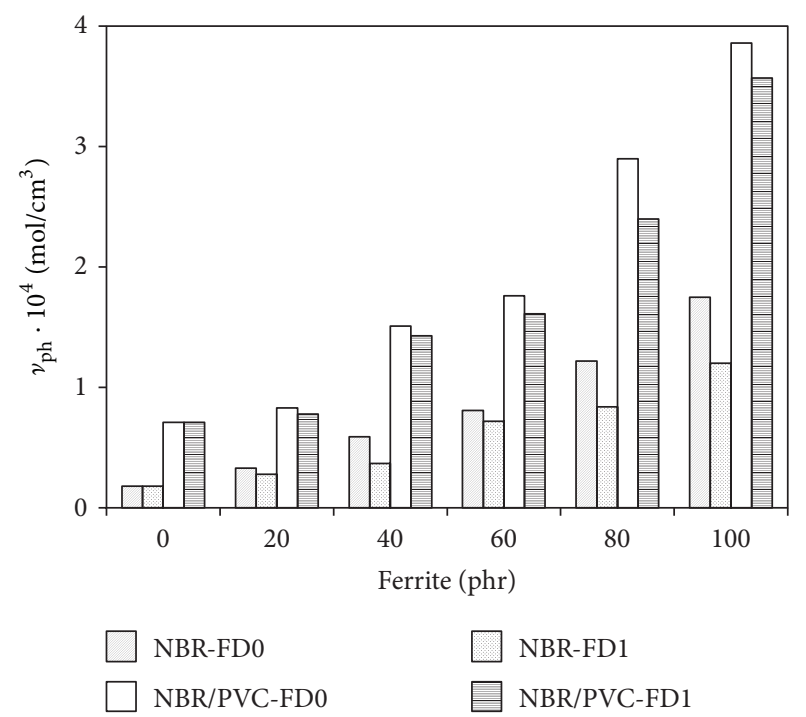

FIGURE 6: Influence of ferrites content on physical cross-link density $\nu_{\mathrm{ph}}$ of composites.

cyano groups in NBR, but also between oxygens and chlorine atoms present in the structure of PVC.

The results also demonstrated that higher values of $v_{\mathrm{ph}}$ in all rubber systems were achieved by applying ferrite modified with PVAL (FD0). The matter of such behavior seems to be the improvement of interactions and adhesion between ferrites and rubber matrices due to the presence of hydroxyl groups of PVAL, which are able to physically interact with oxygen ions of ferrite particles, as well as with polar groups of elastomers. Thus, it can be concluded that PVAL present on the surface of ferrite particles is believed to form interfacial layer between the magnetic filler and the rubber matrices which contributes to the enhancement of the adhesion and compatibility between both components. Thus also improvement in the physical and total cross-link density of rubber magnetic composites was subsequently achieved.

3.2. Influence of Ferrite Content on Physical-Mechanical Properties of Composites. Physical-mechanical properties of prepared composites were evaluated in accordance with the valid technical standards and they are graphically illustrated in Figures 7-11. The modulus M100 of all composites showed increasing trend with increasing amount of magnetic fillers. From Figure 7 it is clearly seen that higher values of modulus exhibited composites based on NBR/PVC. The abovementioned facts can be also applied to modulus M300, but the differences in the values M300 of composites based on NBR and equivalent composites based on NBR/PVC were much higher (Figure 8). The incorporation of strontium ferrites into rubber matrices leads also to the improvement of hardness of magnetic composites (Figure 9). The enhancement of moduli and hardness with increasing content of strontium ferrites can be attributed to the increase in cross-link density of composites with the increase in ferrites loading. Also, as higher cross-link densities $v_{t}, v_{\mathrm{ch}}$, and $\nu_{\mathrm{ph}}$ were evaluated for composites based on NBR/PVC compared to those 

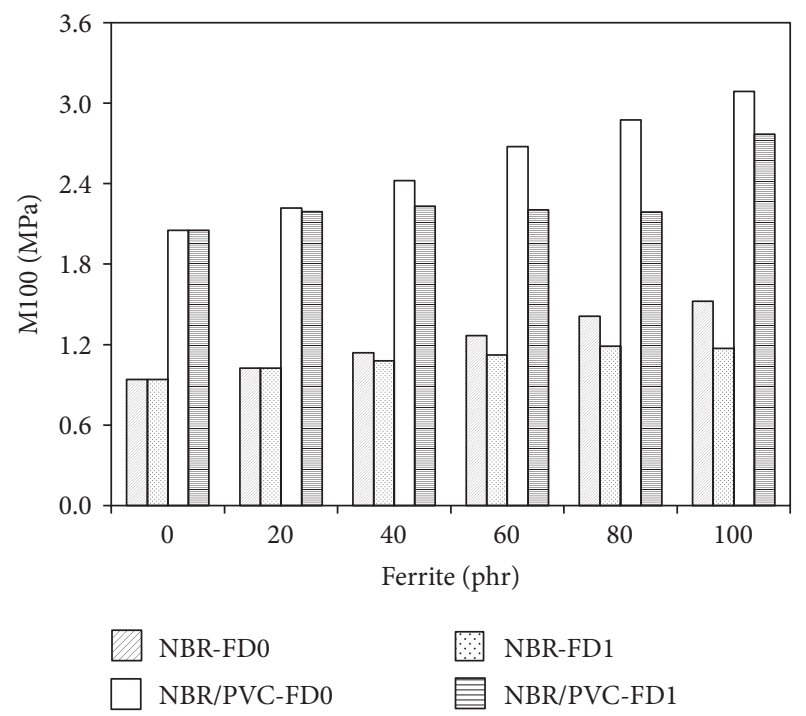

Figure 7: Influence of ferrites content on modulus M100 of composites.

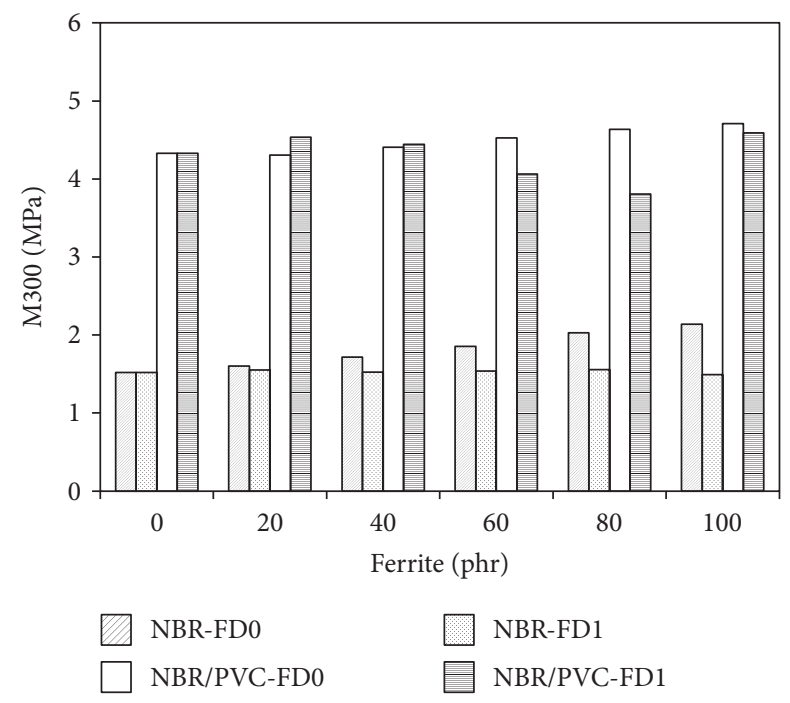

FIGURE 8: Influence of ferrites content on modulus M300 of composites.

of composites based on NBR, these composites were also found to have higher moduli and hardness. And finally, higher cross-link densities of composites filled with modified ferrite FD0 compared to those filled with ferrite FD1 were reflected in higher values of the tested characteristics of the corresponding composites.

From Figure 10 it is possible to observe that no significant changes were recorded in the elongation at break of composites based on NBR/PVC in dependence on strontium ferrites content. On the other hand, the incorporation of magnetic fillers in the rubber compounds based on NBR resulted in the slight increase of elongation at break of the equivalent composites. As shown in Figure 11, the presence of modified ferrite FD0 in both types of rubber systems leads to the improvement of tensile strength of composites.

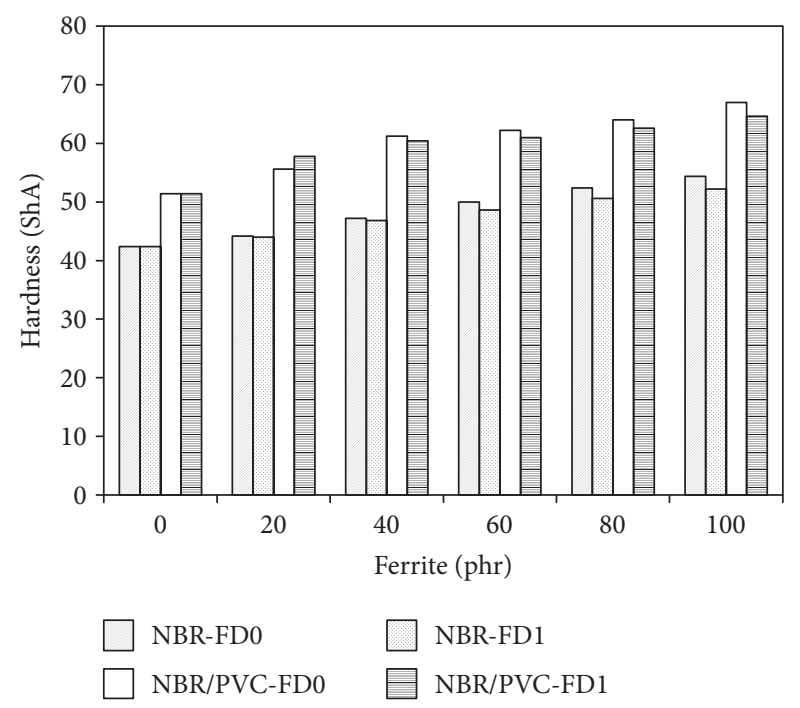

FIGURE 9: Influence of ferrites content on hardness of composites.

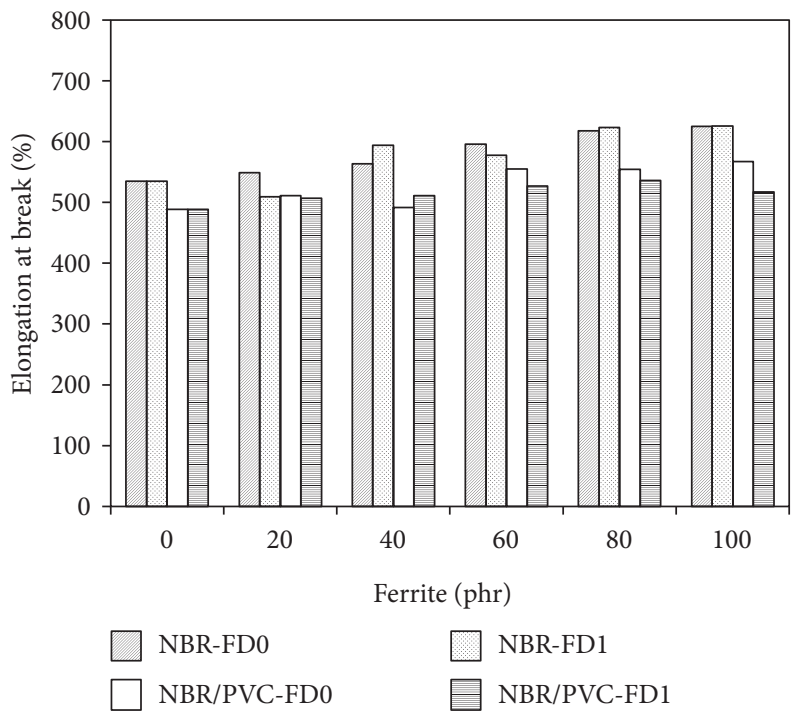

FIGURE 10: Influence of ferrites content on elongation at break of composites.

When FD0 ferrite content increased from 0 to $100 \mathrm{phr}$, the tensile strength of the samples increased from roughly 2.8 to $4.7 \mathrm{MPa}$ in the case of NBR based composites and from approximately 9.7 to $12.9 \mathrm{MPa}$ in the case of NBR/PVC based composites. This represents the increase in tensile strength less than $2 \mathrm{MPa}$ for composites based on NBR and more than $3 \mathrm{MPa}$ for the composites based on NBR/PVC when the amount of ferrite was increased up to its maximum value. The increasing tendency of tensile strength of prepared composites was recorded also by incorporation of unmodified ferrite FD1. Although the tensile strength tends to increase in dependence on FD1 content in both types composites, its values were lower in comparison with the corresponding composites filled with ferrite FD0. The differences in tensile strength of composites filled with ferrites FD0 and FD1 became more evident in the case of samples with higher 


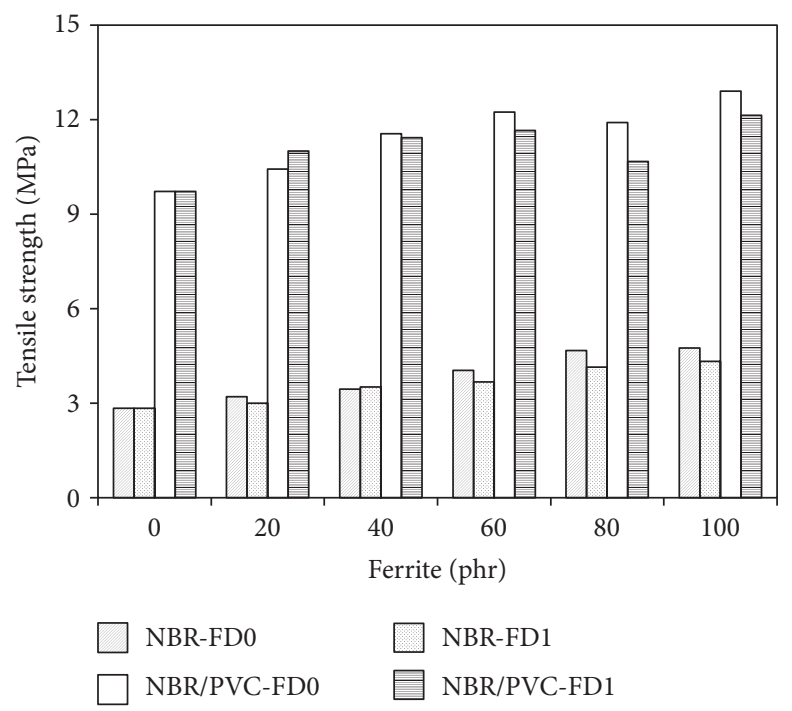

FIGURE 11: Influence of ferrites content on tensile strength of composites.

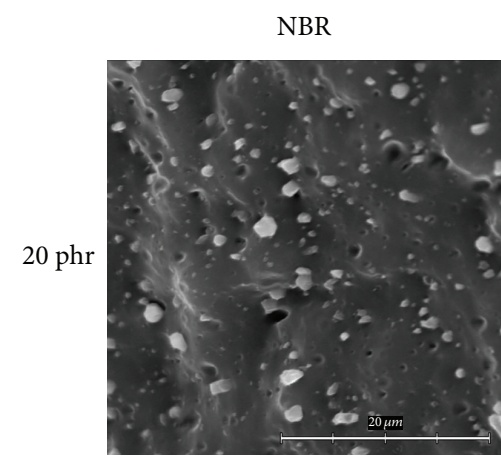

NBR

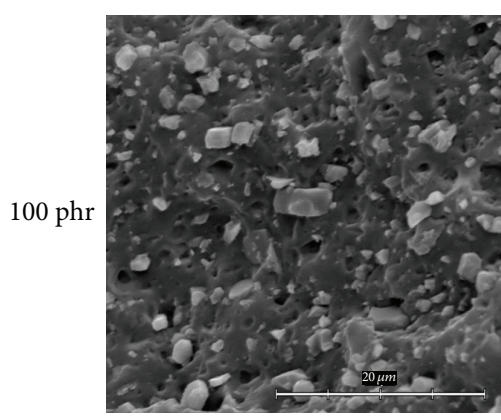

(a)

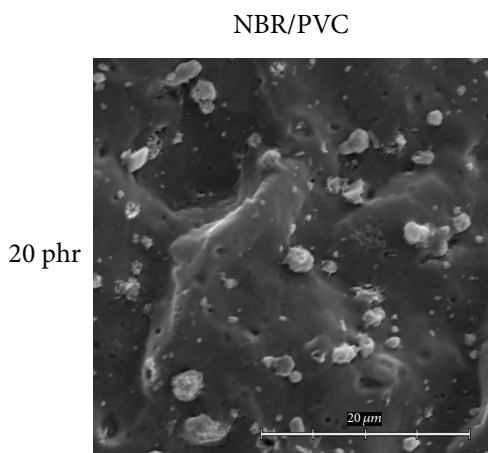

NBR/PVC

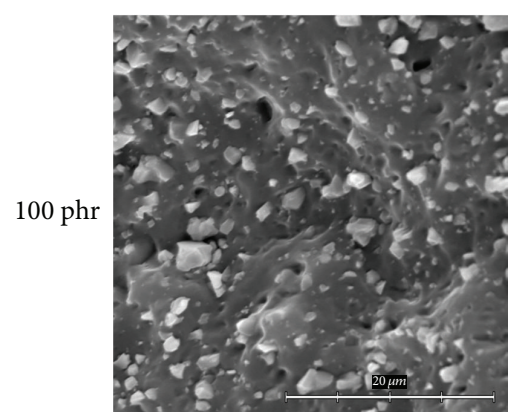

(b)

FIGURE 12: SEM images of composites.

magnetic fillers content. When looking at the tensile strength of composites with lower strontium ferrites content, the type of the used ferrite modification seems not to be significant, as the differences between the values of tensile strength in dependence on the type of ferrite were less visible.

The achieved results showed that ferrites interact with rubber matrices and provide reinforcing effect to the magnetic composites. It can also be stated that the reinforcing effect of incorporated ferrites increases with the increase in polarity of rubber matrices. The results of the study also demonstrated that surface modification of ferrite improves the adhesion and compatibility on the interphase fillerrubber which was subsequently reflected in higher values in cross-link density and physical-mechanical properties of the corresponding composites.

3.3. Microscopic Analysis of Composites. The surface morphology of composites filled with modified ferrite FD0 is presented in Figure 12. The results demonstrated that more homogenous structure showed composites based on 


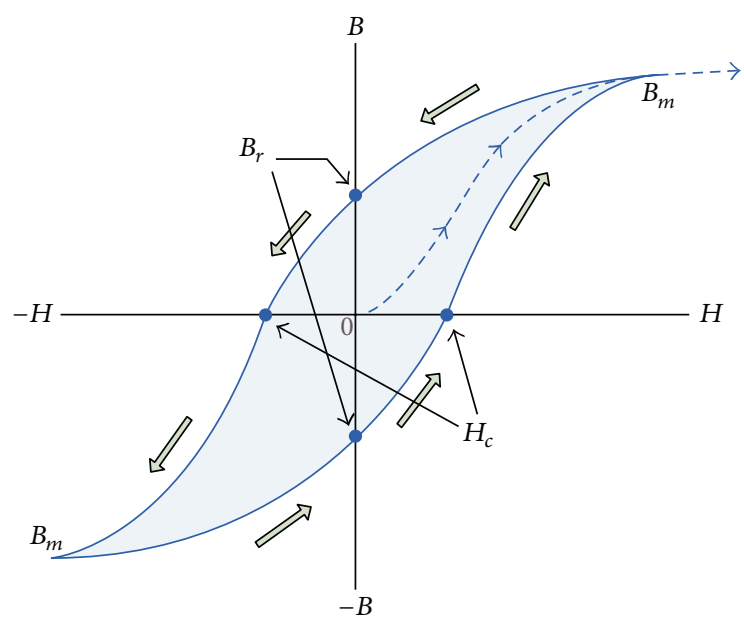

FIGURE 13: Magnetizing curve of magnetic materials.

NBR/PVC (Figure 12(b)), as also outlined in the section above. The adhesion and compatibility between the rubber matrix and the filler are improved due to the higher polarity of the rubber matrix and surface modification of ferrite. In the case of composites based on NBR, the mutual adhesion between the two phases seems to be little worse with existing of more voids and microcavities and on the interphase fillerrubber (Figure 12(a)).

3.4. Influence of Ferrite Content on Magnetic Characteristics of Composites. The dependence of magnetic induction $B$ on intensity of magnetic field $H$ is called magnetizing curves, which provide complete information about technical properties of magnetic substances. Figure 13 illustrates the dependence of magnetic induction $B$ in the material on intensity of magnetic field $H$, when the sample is cyclically magnetized in the presence of external magnetic field. The remanent magnetic induction $B_{r}$, which represents the value of residual magnetism in the material, when an external magnetic field is removed, and the coercive intensity of magnetic field (coercivity, $H_{c}$ ), which represents energy needed to abolish the remanent magnetic induction, are the most important parameters of all permanent magnets. The higher values of both characteristics magnetic materials have, the better permanent magnets they are. Magnetic hard materials, as also ferrites, usually exhibit high values of both magnetic characteristics. The incorporation of strontium ferrites should also impart magnetic properties to the nonmagnetic rubber matrix. Therefore the dependence of magnetic properties of tested composites on ferrites loading was investigated.

The values remanent magnetic induction $B_{r}$ and coercivity $H_{c}$ for all prepared composites are graphically illustrated in Figures 14 and 15. From Figure 14 it becomes clearly apparent that the remanent magnetic induction of all composites showed significant increasing tendency with increasing content of magnetic fillers. When the content of strontium ferrites increased from 20 up to $100 \mathrm{phr}$, the value of $B_{r}$ increased in more than $400 \%$ in all cases. By contrast, the coercivity of composites was not influenced by

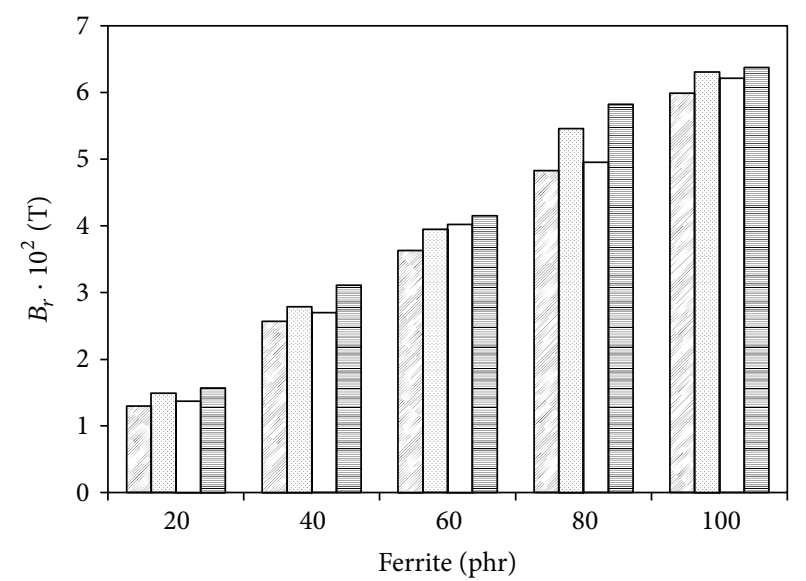

NBR-FD0

NBR-FD1

NBR/PVC-FD0 国 NBR/PVC-FD1

FIGURE 14: Influence of ferrites content on remanent magnetic induction $B_{r}$ of composites.

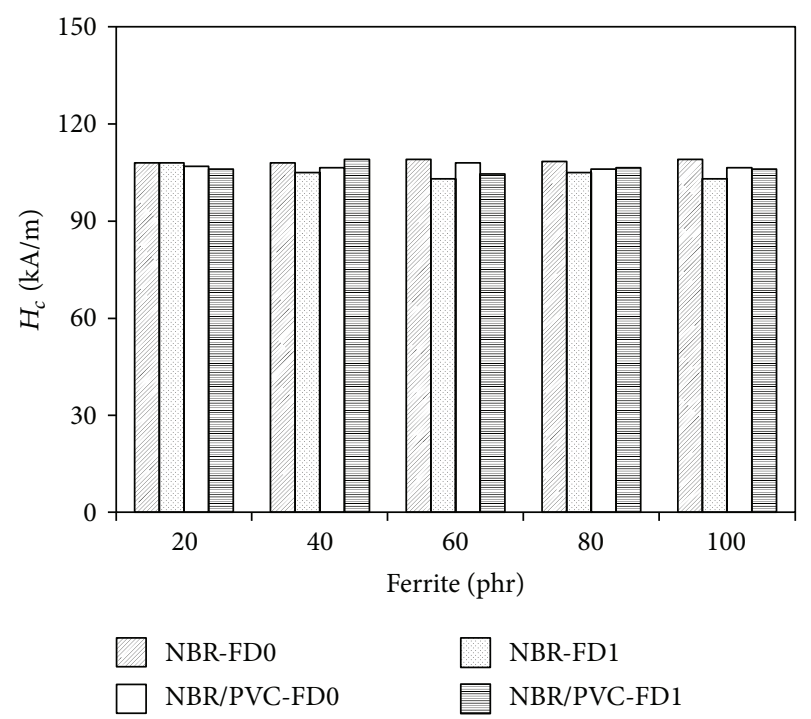

FIGURE 15: Influence of ferrites content on coercivity $H_{c}$ of composites.

the amount of magnetic fillers, as its values were moved only in the low range of experimental values (Figure 15). As also seen in Figures 14 and 15, both magnetic characteristics were not influenced neither by type of strontium ferrite nor by the type of rubber matrix. It becomes evident that the incorporation of strontium ferrites into rubber matrices markedly influences the remanent magnetic induction of the composites with no relevant effect on the coercivity.

\section{Conclusion}

In this study, rubber magnetic composites were prepared by incorporation of strontium ferrite in modified and unmodified form into rubber matrices based on NBR and NBR/PVC. The main objective was to investigate the properties of the 
prepared composites with respect to the polarity of the rubber matrices and modification of ferrite.

The results demonstrated that the adhesion between the rubber and filler is higher in the case of composites based on NBR/PVC due to higher polarity of the rubber matrix. Surface modification of ferrite contributed to the improvement of interactions on the interphase filler-rubber which was subsequently reflected in the enhancement of the observed properties of the prepared composite materials. Finally, it can be stated the ferrite incorporated in the tested rubber matrices provides reinforcing effect to the rubber magnetic composites.

\section{Competing Interests}

The authors declare that they have no competing interests.

\section{Acknowledgments}

This work was supported by the Slovak Research and Development Agency under Contract no. APVV069412.

\section{References}

[1] K. Yadhu, Ch. Shine, U. Nazeeha, T. R. Smitha, P. S. Parameswaran, and K. H. Prema, "Processability, mechanical and magnetic studies on natural rubber-ferrite composites," International Journal of Chemical Studies, vol. 3, no. 1, pp. 15-22, 2015.

[2] R. Pattanayak, R. Muduli, R. K. Panda et al., "Investigating the effect of multiple grain-grain interfaces on electric and magnetic properties of $\left[50 \mathrm{wt} \% \mathrm{BaFe}_{12} \mathrm{O}_{19}-50 \mathrm{wt} \% \mathrm{Na}_{0.5} \mathrm{Bi}_{0.5} \mathrm{TiO}_{3}\right]$ composite system," Physica B: Condensed Matter, vol. 485, pp. 67-77, 2016.

[3] P. Martins, C. M. Costa, G. Botelho, S. Lanceros-Méndez, J. M. Barandiaran, and J. Gutiérrez, "Dielectric and magnetic properties of ferrite/poly(vinylidene fluoride) nanocomposites," Materials Chemistry and Physics, vol. 131, no. 3, pp. 698705, 2012.

[4] S.-Y. Tong, M.-J. Tung, W.-S. Ko et al., "Effect of Ni fillers on microwave absorption and effective permeability of $\mathrm{NiCuZn}$ ferrite/Ni/polymer functional composites," Journal of Alloys and Compounds, vol. 550, pp. 39-45, 2013.

[5] F. S. Bellucci, F. C. Lobato De Almeida, M. A. Lima Nobre, M. A. Rodríguez-Pérez, A. T. Paschoalini, and A. E. Job, "Magnetic properties of vulcanized natural rubber nanocomposites as a function of the concentration, size and shape of the magnetic fillers," Composites Part B: Engineering, vol. 85, pp. 196-206, 2016.

[6] D. E. El-Nashar, N. M. Ahmed, and W. R. Agami, "The effect of new ferrite/kaolin pigment on the properties of acrylonitrilebutadiene rubber composites," Materials and Design, vol. 52, pp. 108-117, 2013.

[7] J. Kruželák, R. Sýkora, R. Dosoudil, and I. Hudec, "Magnetic composites prepared by incorporation of strontium ferrite into polar and non-polar rubber matrices," Polymer Composites, 2015.

[8] J. Kruželák, M. Ušaková, R. Dosoudil, I. Hudec, and R. Sýkora, "Microstructure and performance of natural rubber based magnetic composites," Polymer-Plastics Technology and Engineering, vol. 53, no. 11, pp. 1095-1104, 2014.
[9] J. Kruželák, R. Sýkora, R. Dosoudil, and I. Hudec, "Influence of peroxide curing systems on the performance of natural rubberbased magnetic composites," Composite Interfaces, vol. 22, no. 6, pp. 473-488, 2015.

[10] P. Martins, C. M. Costa, M. Benelmekki, and S. LancerosMendez, "Preparation of magnetoelectric composites by nucleation of the electroactive $\beta$-phase of poly(vinylidene fluoride) by $\mathrm{NiZnFe}_{2} \mathrm{O}_{4}$ nanoparticles," Sensor Letters, vol. 11, no. 1, pp. 110-114, 2013.

[11] S. Das, G. C. Nayak, S. K. Sahu, P. C. Routray, A. K. Roy, and $\mathrm{H}$. Baskey, "Microwave absorption properties of doublelayer composites using CoZn/NiZn/MnZn-ferrite and titanium dioxide," Journal of Magnetism and Magnetic Materials, vol. 377, pp. 111-116, 2015.

[12] E. C. Milke, M. Rei, J. P. de Souze, and L. Schaeffer, "Powder injection molded strontium-ferrite magnets," International Journal of Powder Metallurgy, vol. 37, no. 5, pp. 47-51, 2001.

[13] K. H. Mahmoud and M. H. Makled, "Infrared spectroscopy and thermal stability studies of natural rubber-barium ferrite composites," Advances in Chemical Engineering and Science, vol. 2, no. 3, pp. 350-358, 2012.

[14] Y. F. Wang, Q. L. Li, C. R. Zhang, and H. X. Jing, "Preparation and magnetic properties of different morphology nano$\mathrm{SrFe}_{12} \mathrm{O}_{19}$ particles prepared by sol-gel method," Journal of Alloys and Compounds, vol. 467, no. 1-2, pp. 284-287, 2009.

[15] J. Li, H.-F. Zhang, G.-Q. Shao et al., "Synthesis and properties of new multifunctional hexaferrite powders," Procedia Engineering, vol. 102, pp. 1885-1889, 2015.

[16] L. Lechevallier and J. M. Le Breton, "Substitution effects in Mtype hexaferrite powders investigated by Mössbauer spectrometry," Journal of Magnetism and Magnetic Materials, vol. 290-291, part 2, pp. 1237-1239, 2005.

[17] K. B. Paul, "Magnetic and structural properties of Ba M-type ferrite-composite powders," Physica B: Condensed Matter, vol. 388, no. 1-2, pp. 337-343, 2007.

[18] T. Xie, L. Xu, C. Liu, S. Ding, J. Yang, and W. Wu, "Synthesis and adsorption properties of high specific surface area strontium ferrite from Industrial Strontium Residue," Vacuum, vol. 93, pp. 71-78, 2013.

[19] P. Saramolee, P. Lertsuriwat, A. Hunyek, and C. Sirisathitkul, "Cure and mechanical properties of recycled NdFeB-natural rubber composites," Bulletin of Materials Science, vol. 33, no. 5, pp. 597-601, 2010.

[20] S. Vinayasree, M. A. Soloman, V. Sunny, P. Mohanan, P. Kurian, and M. R. Anantharaman, "A microwave absorber based on strontium ferrite-carbon black-nitrile rubber for $\mathrm{S}$ and X-band applications," Composites Science and Technology, vol. 82, pp. 69-75, 2013.

[21] J. Gutiérrez, P. Martins, R. Gonçalves et al., "Synthesis, physical and magnetic properties of $\mathrm{BaFe}_{12} \mathrm{O}_{19} / \mathrm{P}(\mathrm{VDF}-\mathrm{TrFE})$ multifunctional composites," European Polymer Journal, vol. 69, pp. 224-231, 2015.

[22] H. S. Jung, S. H. Kwon, H. J. Choi, J. H. Jung, and Y. G. Kim, "Magnetic carbonyl iron/natural rubber composite elastomer and its magnetorheology," Composite Structures, vol. 136, pp. 106-112, 2016.

[23] G. Kraus, “Swelling of filler-reinforced vulcanizates," Journal of Applied Polymer Science, vol. 7, no. 3, pp. 861-871, 1963. 
[24] G. R. Hamed, Materials and Compounds, Oxford University Press, New York, NY, USA, 1992.

[25] R. C. Pullar, "Hexagonal ferrites: a review of the synthesis, properties and applications of hexaferrite ceramics," Progress in Materials Science, vol. 57, no. 7, pp. 1191-1334, 2012. 

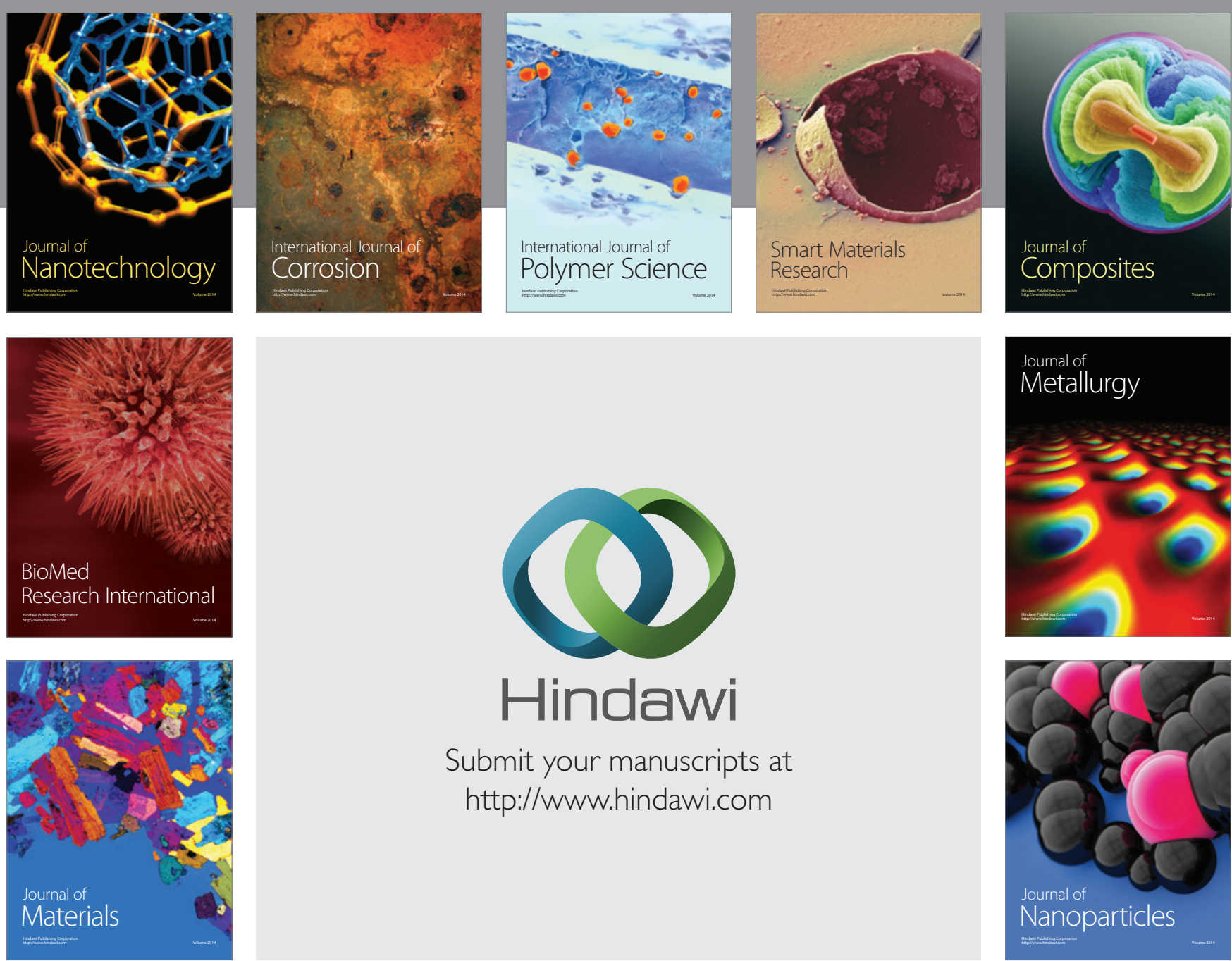

\section{Hindawi}

Submit your manuscripts at

http://www.hindawi.com

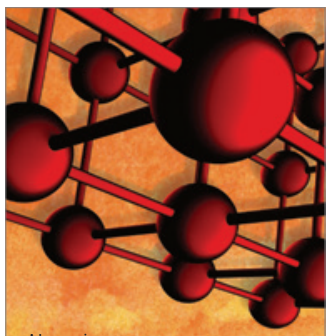

Materials Science and Engineering
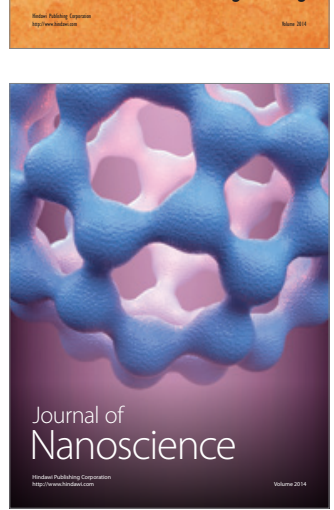
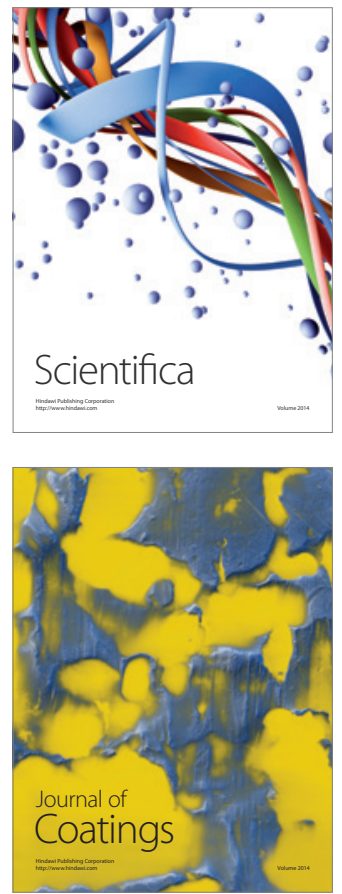
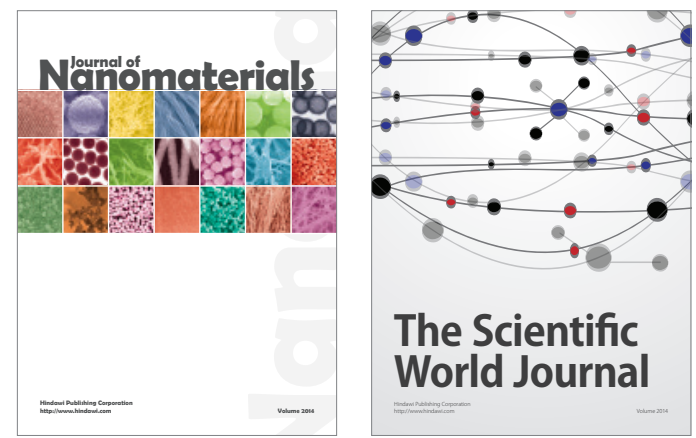

The Scientific World Journal
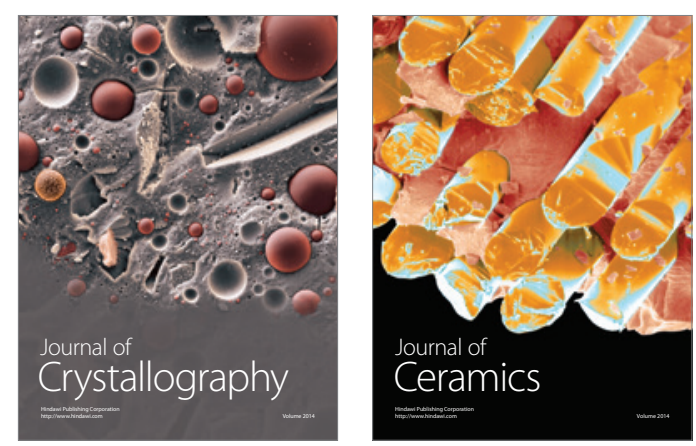
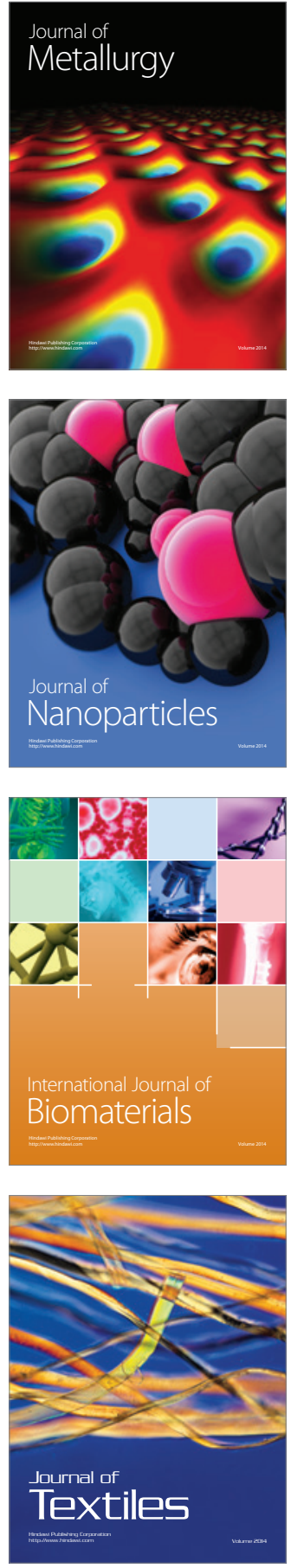